\title{
O Imaginário dos Pacientes acerca da Doença Renal Crônica
}

\author{
Sebastião Elan dos Santos Limal e Joel Lima Júnior ${ }^{2}$
}

\begin{abstract}
Resumo: A Doença Renal Crônica é constituída como uma enfermidade causada por lesão ou perda progressiva e irreversível das funções dos rins, sendo um importante problema médico e de saúde pública. O presente trabalho trata-se de um estudo qualitativo, realizado através de entrevistas semi-estruturadas junto a sete pacientes da UNIRIM Crato-Ce, que realizam hemodiálise três vezes por semana. O estudo objetivou compreender as imagens acerca da doença renal crônica elaborada por estes pacientes. Os resultados mostraram um impacto nas diversas áreas da vida dos entrevistados, desde o diagnóstico e periodicidade nas sessões de hemodiálise. $\mathrm{O}$ desconhecimento sobre a doença e tratamento hemodialítico influenciam de forma negativa para o indivíduo. A família apresentou-se como elemento principal na aderência ao tratamento, e a busca de sentidos e forças para enfrentar diariamente a doença foi encontrada na figura de Deus. Um trabalho que englobe o resgate de sentidos, a ressignificação do sofrimento e intervenções mais humanas e com boa vinculação entre equipe assistencial e paciente torna-se essencial no processo de cuidado.
\end{abstract}

Palavras-Chave: Doença Renal Crônica; Hemodiálise; Família.

\section{The Imaginary of Patients about Chronic Kidney Disease}

\begin{abstract}
The Chronic Kidney Disease is constituted as a disease caused by injury or progressive, irreversible loss of kidney function, is a major medical and public health problem. The present paper is a qualitative study, using semi-structured interviews with seven patients UNIRIM Crato-CE, on hemodialysis three times a week. The study aimed to understand the images on the Chronic Kidney Disease produced by these patients. The results showed an impact on the life of the subject in its various areas of life, from diagnosis and periodically during dialysis sessions. Lack of knowledge about the disease and the hemodialysis influence negatively to the individual. The family was presented as the main element in their treatment, and the pursuit of meaning and strength to face daily the disease was found in the figure of God. A work that encompasses the redemption of senses, reframing suffering, and humane and good linkage between care team and patient interventions is essential in the care process.
\end{abstract}

Keywords: Chronic Kidney Disease; Hemodialysis; Family.

\section{Introdução}

O rim exerce uma função muito importante no organismo e a Doença Renal Crônica (DRC) é constituída como uma enfermidade causada por lesão ou perda progressiva e irreversível da função dos rins, impossibilitando que ele exerça funções vitais para o equilíbrio e homeostasia do organismo.

Romão Junior em 2004 já colocava que a doença renal crônica apresentava-se como um importante problema médico e de saúde pública. Para tanto as formas de tratamento para a DRC é a terapia renal substitutiva, apresentada pela grande maioria das vezes com a hemodiálise e o transplante renal.

\footnotetext{
${ }^{1}$ Acadêmico do curso de Psicologia da Faculdade Leão Sampaio (FALS). E-mail: lynck16@ hotmail.com.

${ }^{2}$ Docente da Faculdade Leão Sampaio. Mestre em Ciências da Saúde, pela Universidade Federal do Rio Grande do Norte (UFRN). E-mail: joellima@leaosampaio.edu.br.
} 
A Insuficiência Renal Crônica (IRC) provoca no paciente uma série de mudanças que se fazem necessários novos reajustes no estilo de vida para que o mesmo consiga viver com uma melhor qualidade de vida frente à doença. O bem-estar psicológico torna-se muito importante nesse cenário, uma vez que a dependência do uso da máquina de diálise pode trazer um estresse adicional. Adotar uma nova postura e dá sentidos a sua vida diante da nova realidade é muito importante.

Trabalhar as imagens acerca da DRC elaborada pelo paciente é necessário para que se possa acessar o imaginário e percepções do indivíduo em estado de cronicidade. Compreender o seu mundo e como os mesmos se percebem frente a hemodiálise, favorece para uma aproximação com as suas realidades e uma terapêutica voltada para as suas necessidades.

De acordo com o supracitado, pode-se perceber o quão importante e relevante é esse assunto, uma vez que os envolvidos no processo de tratamento e cuidados serão favorecidos ao adotarem intervenções satisfatórias e eficazes.

O presente artigo tem como objetivo compreender de que forma o paciente renal crônico se relaciona com a DRC, ao analisar as transformações advindas com a doença e hemodiálise, estratégias utilizadas para enfrentar a doença e a participação da família no processo de enfrentamento e cuidado.

\section{A Insuficiência Renal Crônica}

A DRC é hoje considerada um problema mundial de saúde pública. Sendo o rim um importante órgão para manter o organismo como um todo em estado de homeostase, uma vez comprometida a função renal, todo os outros órgãos sofrem complicações (BASTOS; BREGMAN; KIRSZTAJN , 2010).

Freitas e Cosmos (2010) colocam que o rim é um órgão muito importante no organismo, sendo o principal do aparelho urinário, possuindo funções como a filtragem do sangue para eliminação de resíduos tóxicos, regulação da pressão arterial, controle de líquidos e químicos no organismo.

A IRC é uma doença que tem como principal causa a diabete melittus e a hipertensão arterial, provocando lesão nos rins com perda progressiva e irreversível de sua função. A doença renal compromete o metabolismo e a vida celular de todos os órgãos do corpo. Com alto índice de mortalidade e morbidade, afeta as relações e a qualidade de vida dos pacientes (FREITAS; COSMOS, 2010).

A IRC é representada por uma redução ou limitação da capacidade do rim de realizar a filtração glomerular, causando uremia, como consequência esse órgão perde a capacidade de eliminar as substâncias tóxicas do organismo, por não conseguir filtrar e excretar pelo rim (MASCARENHAS et al, 2010). 
De acordo com Bastos; Bregman e Kirsztajn (2010) alguns pacientes apresentam suscetibilidades maior a adquirir a DRC. Dentre os que estão no grupo de risco; encontram-se os pacientes diabéticos, hipertensos, idosos, com doenças cardiovasculares, com histórico de familiares com DRC e pacientes que usam medicações nefrotóxicas.

Para Mascarenhas et al (2010) as três causas mais comuns da IRC são Diabetes, Hipertensão e Glomerulonefrite. Esses autores trazem dados da Sociedade Brasileira de Nefrologia com estimativa de que a cada dez pessoas no mundo, uma sofra de IRC. Ainda apresenta que estudos recentes indicam uma relação direta entre a DRC e baixos níveis socioeconômicos, reflexos de pouca acessibilidade aos serviços de saúde e conseqüente falta de prevenção de doenças como diabetes e hipertensão.

De acordo com os autores supracitados, pode-se inferir que políticas de prevenção e promoção nas Estratégias de Saúde da Família (ESF), por exemplo, podem diminuir em muito o risco de mortalidade de pacientes que já se encontram com sua função renal comprometida, uma vez que precocemente descoberta a doença renal, o paciente pode mudar hábitos e preocupar-se com problemas como a diabete e hipertensão, visto pelos autores acima citados como umas das causas mais comuns da doença.

Como o próprio nome sugere, trata-se de uma doença crônica que não possui expectativas de cura. Para tanto, quando a função renal estiver menor que $12 \%$ ou $10 \%$, começa-se a pensar em formas de tratamento substitutivo que realize a função que o rim não consegue executar, sendo métodos como a hemodiálise ou transplante renal (MASCARENHAS et al, 2010).

A hemodiálise é uma forma de tratamento a qual limpa e filtra o sangue do paciente, controlando a pressão arterial e na eliminação de líquidos e substâncias químicas, onde a circulação do sangue é feita fora do organismo. O transplante é também uma das formas de tratamento e não de cura, o paciente submetido a essa modalidade necessita de acompanhamento medicamentoso por toda a vida (FREITAS; COSMOS, 2010).

O tratamento hemodialítico provoca um grande impacto na vida do paciente renal, desde o seu diagnóstico, pelo desgaste emocional e pela dependência que é causada com a máquina de hemodiálise, com repercussões nas diversas áreas, seja pessoal, familiar ou social do paciente (MASCARENHAS et al, 2010).

O transplante de órgãos é uma opção de tratamento que proporciona uma melhor qualidade de vida para os pacientes que não obtiveram êxito em outros meios de tratamentos convencionais. Fazendo-se necessária uma investigação criteriosa com os pacientes, onde deve ser analisados fatores de riscos, aspectos psicológicos e cognitivos (KNOBEL, 2008).

Melo Filho et al, ao falar sobre transplante renal diz que ele "se apresenta como uma alternativa para uma melhor qualidade de vida, livrando os pacientes dos transtornos habituais" (2010, p.376), que são gerados pela dependência da máquina e grande frequência de idas às clínicas de hemodiálise. 
Resende et al (2007) coloca que a hemodiálise é responsável por um ambiente monótono e restrito, do qual exige muito tempo do paciente que realizam sessões de 3 a 5 horas, dependendo da sua necessidade, com frequência de três vezes por semana.

Neste cenário, infere-se o quão comprometido fica a vida do paciente renal, por a doença afetar aspectos fisiológicos e físicos, psicológicos, sociais, assim como mudanças alimentares e no estilo de vida de um modo geral, que requerem do paciente uma postura frente à doença e um tratamento que contribua para a manutenção de uma qualidade de vida satisfatória.

\section{Aspectos Psicológicos da Doença Renal Crônica}

Esta enfermidade exige uma adaptação por gerar uma crise no paciente e os familiares que o acompanham, abalando então, as suas interações sociais. As periodicidades das sessões de diálise, as limitações e adaptações a nova dieta alimentar, assim como a vivência constante em hospitais e clínicas de diálise, geram muita ansiedade e tensão nos pacientes que juntos com a esperança de um transplante, esperam por uma mudança de vida. (HIGA et al, 2008).

A Doença Renal Crônica traz várias perdas e mudanças na vida do paciente e o tratamento da DRC provoca um estresse adicional exigindo adaptações significativas na vida pessoal, na alimentação, nas rotinas medicamentosas, criando assim uma série de novas relações de dependência. (FREITAS; COSMOS, 2010)

Para que as resistências, quanto ao processo assistencial sejam menores, faz-se necessário que o paciente consiga lidar com essa realidade, aceitando a mesma. Resende et al (2007) coloca que é importante que o paciente consiga se aceitar nas suas diversas características positivas e negativas, contribuindo assim para melhora nas relações consigo e com os outros. Esse processo é fundamental para que se viva diante da doença com melhor qualidade.

Em um estudo feito por Takemoto et al (2011) ao avaliar a qualidade de vida em idosos que realizam hemodiálise, os resultados apresentam que apesar desse tratamento ser monótono e limitar em muito a vida dos pacientes, no entanto, o mesmo prolonga a vida do sujeito impedindo futuras complicações. Por conta do tratamento dialítico, os pacientes sofrem menos complicações. Nesse mesmo estudo os indivíduos percebiam a hemodiálise como uma forma de manutenção do seu bemestar e melhora da qualidade de vida.

O resgate de sentidos para a vida do paciente renal crônico é de fundamental importância para que o mesmo consiga dar novos significados ao seu sofrimento e crie possibilidades futuras que facilitem sua adesão ao tratamento e consequente melhora da qualidade de vida. A esse respeito Frankl (2008) coloca que é muito importante que o sujeito consiga encontrar o seu para que viver, esse que conseguirá enfrentar quase todo como viver. 


\section{Doença Renal Crônica e Família}

A DRC exige do paciente um processo de adaptação ao novo estilo de vida, fazendo-se necessário que o paciente se ressignifique e crie novas estratégias para enfrentamento da doença, como consequência essas mudanças afetam todo o sistema familiar e cuidadores que vivem em contato direto com o paciente. “(...) a família funciona como um sistema que tende à homeostasia, é possível dizer que, quando um membro desse sistema familiar adoece, todo o grupo sofre impacto" (KNOBEL, 2008, p. 71). Esse mesmo autor cita que quando o quadro for crônico, há uma mudança radical na estrutura familiar por fracassar na tentativa de voltar ao equilíbrio anterior.

Os pacientes muitas vezes encontram na sua família e/ou cuidador, forças para prosseguirem no tratamento. Kubler-Ross (2008) coloca que a relação dos familiares com o paciente é muito importante para um tratamento satisfatório e a equipe de saúde que o assiste deve levar em consideração a família do paciente para que o atendimento seja mais completo. Muitas vezes o sujeito adoecido encontra na sua família e/ou cuidador forças para prosseguirem diante de situação tão difícil.

Ferreira et al (2012) aborda que os significados da doença não é exclusivo dos pacientes, mas também dos familiares e da rede social do qual o mesmo está inserido, sendo necessários reajustes na estrutura familiar para melhor adequar a realidade do paciente que agora adere o papel de doente na família. O autor afirma que o papel de cuidador torna-se desgastante, para tanto é necessário uma assistência voltada para esses sujeitos com o propósito de atenuar esse desgaste.

O mesmo autor acima citado, ao fazer uma comparação de cuidadores de pacientes com doenças crônicas e com o público em geral, percebeu que "cuidadores de portadores de doença crônica apresentam significantemente mais sintomas de distúrbios do humor como ansiedade e depressão" (FERREIRA et al, 2012, p. 279).

Percebe-se que uma intervenção adequada e global envolveria não apenas o paciente adoecido, mas sim, expandindo para seus familiares e/ou cuidadores, que também estão implicados no processo de adoecimento, seja pela mudança e adequação à nova realidade do ente ou pelos próprios cuidados e dinâmica familiar que é alterada.

\section{Método}

\section{Universo da Pesquisa}

Este estudo classifica-se como pesquisa de campo de cunho qualitativo, exploratória e descritiva, visando compreender da forma mais fidedigna as vivências e percepções dos pacientes renais crônicos a respeito do seu adoecimento e transformações advindas com a DRC. Marconi e 
Lakatos (2011, p. 269) colocam que a metodologia qualitativa tem como preocupação em "analisar e interpretar aspectos mais profundos, descrevendo a complexidade do comportamento humano. [...] as amostras são reduzidas, os dados são analisados em seu conteúdo psicossocial”. No que se refere à pesquisa de campo, essa tem como objetivo conseguir novos conhecimentos e soluções a respeito de um dado problema (MARCONI; LAKATOS, 2010).

No que diz respeito à pesquisa exploratória, essa tem o objetivo de buscar o maior número de informações possíveis, por parte do entrevistador, proporcionando um maior conhecimento acerca do assunto pesquisado. No que se trata de descritivo, esse tipo de estudo busca sem manipulação, as descrições dos sujeitos envolvidos, utilizando de observações e análises dos dados que foram coletados (GIL, 2010).

O presente trabalho foi realizado na Unidade de Diálise e Transplante renal Dr. Raimundo Bezerra (UNIRIM), localizada na cidade do Crato, Ceará. A clínica é um serviço de saúde suplementar, instituição privada e conveniada ao Sistema Único de Saúde (SUS), tendo como finalidade realizar tratamento especializado com uma equipe multidisciplinar (médicos nefrologistas, enfermeiros, psicólogos, assistentes sociais, nutricionistas e técnicos em enfermagens), para melhor atender aos pacientes com insuficiência renal crônica, visando promover a assistência através de um atendimento humanizado e de qualidade, considerando as necessidades de cada paciente e o estágio de sua doença.

Nessa instituição é realizada a hemodiálise, a Diálise Peritoneal Ambulatorial Continua (CAPD), Diálise Peritoneal Intermitente (DPI), transplante renal e consultas ambulatoriais para acompanhamento dos pacientes transplantados (pós-tx).

A UNIRIM atende aos pacientes da região do Cariri e de diversas cidades circunvizinhas que utilizam o serviço. Os atendimentos são realizados de acordo com a necessidade de cada paciente que se dividem em duas turmas (da segunda, quarta e sexta e os da terça, quinta e sábado), com três turnos de diálises (horário A das 7 às 11 horas; horário B das 11às 15 horas e horário C das 15 às 19 horas). Cada sessão de hemodiálise dura em média de 3 a 4 horas.

\section{Sujeitos}

A amostra foi composta por 7 (sete) pacientes que realizam hemodiálise na UNIRIM. O critério de inclusão se deu com a disponibilidade dos pacientes que se encontravam com estado de saúde equilibrado no momento da coleta, mediante assinatura do Termo de Consentimento Livre e esclarecido (TCLE).

Com base nos dados sociodemográficos, pode-se verificar que da amostra composta, 4 (quatro) eram do sexo feminino e 3 (três) do sexo masculino. Com idades entre 41 (quarenta e um) e 72 (setenta e dois) anos. No quesito estado civil 5 (cinco) são casados, 1 (um) é viúvo e 1 (um) 
solteiro. Quanto a possuir outras doenças apenas dois pacientes relatam terem diabetes e hipertensão. Em se tratando da escolaridade, foi observado que 1 (um) participante não possui escolaridade, 5 (cinco) possuem o Ensino Fundamental incompleto e apenas 1 (um) possui nível superior completo. Quanto à profissão, todos abandonaram as suas ocupações antigas e recebem beneficio do governo. No tocante a religião, apenas 1 (um) se classifica como evangélico e 6 (seis) como católicos. No que se refere ao tempo de hemodiálise, os pacientes entrevistados encontram-se entre 9 (nove) meses a 5 (cinco) anos de tratamento. Referente à renda familiar, os pacientes possuem renda mensal entre 1 (um) e 2 (dois) salários mínimos e meio.

\section{Procedimentos}

Na realização da coleta de dados, foi utilizada uma entrevista semi estruturada, além do questionário sociodemográfico. Utilizou-se de dezesseis perguntas gerais, cada uma estruturada para contemplar os objetivos propostos. Algumas questões norteadoras são: (1) O que mais mudou em sua vida após a doença renal?; (2) O que você fez quando a doença começou a aparecer? (estratégias de enfrentamento); (3) O que é qualidade de vida para você?; (4) Como você enxerga a sua qualidade de vida?; (5) O que lhe deu força para enfrentar a doença?; (6) Como sua família lida com seu adoecimento? e (7) Qual o significado da vida para você?.

As entrevistas foram realizadas em uma sala reservada exclusivamente para a coleta de dados. Os participantes previamente aceitaram as condições da entrevista com a assinatura do Termo de Consentimento Livre e Esclarecido (TCLE). As mesmas foram gravadas e transcritas na íntegra pelo pesquisador responsável.

\section{Análise dos Dados}

Para análise dos dados foi utilizada como referência Demartini (1988) que traz a proposta de análise conteúdo. Onde a coleta do material pode ser gravada e transcrita da forma mais fidedigna possível, prezando sempre pela integridade do conteúdo e uma transcrição fiel ao material coletado. Nesse processo a autora fala que são muitas percepções que ficaram na memória do entrevistador podendo se utilizar como suporte para uma melhor contextualização e análise do material coletado.

Na perspectiva de análise de conteúdo com base em Demartine (1988) os relatos contidos serão compostos pela transcrição das entrevistas, com implicações do entrevistador que ao participar da pesquisa, tem memórias de momentos marcantes e percepções importantes do material coletado. Dessa forma a contextualização do lócus da pesquisa irá perpassar pelas imagens e percepções do entrevistador, que frente à transcrição fidedigna do material coletado, irá contribuir para melhor elucidar o que foi pesquisado. 


\section{Discussões dos Resultados}

\section{O Momento do Diagnóstico}

Campos e Turato (2010) colocam que o acometimento da doença seja ela aguda ou crônica, provoca uma série de sentimentos e fatores, que inicialmente, o paciente não estava preparado para enfrentar. O indivíduo ao tomar consciência do diagnóstico e início do tratamento dialítico, sofre uma ruptura com seu estilo de vida passada e enfrenta uma nova condição com limitações que em muito impedem de realizar suas atividades cotidianas. Nas sequências discursivas a seguir é possível identificar tal ideia.

Rapaz, eu vou te dizer, foi um problema foi [...] eu não gosto nem de me lembrar, aqui no hospital eu quase endoidei, fiquei maluco, que eu trabalhava né? Quando eu imaginei que não podia mais trabalhar [...] eu cai em desespero, eu cai em desespero, por que você sabe esse problema que a gente é da roça que sente que não pode mais trabalhar, o caba se sente (E4M54) ${ }^{17}$

Foi difícil viu? Foi muito difícil, minha irmã ficou comigo, ela que me deu a maior força, mas eu não queria aceitar, com o tempo; acho que com 1 mês ou 2 eu cheguei e comecei a aceitar, que é o jeito né? (E1F48)

Foi lá no Recife, o médico me explicou bem direitim e falou pra mim que a alternativa de eu viver era fazer hemodiálise [...] reagi bem, por que as pessoas falam que a pior vida é pior do que morrer (E6M44)

O momento do diagnóstico da doença renal crônica é bem crítica para o paciente que se ver na obrigação de enfrentar uma nova realidade e adaptar-se as limitações e restrições imposta pela doença.

$\mathrm{Na}$ fala acima do Sujeito E4, verifica-se a sua angústia inicial ao descobrir a necessidade de realizar o tratamento dialítico, causado pela impossibilidade de prosseguir nas suas atividades laborais.

Percebe-se nas sequências discursivas E1 e E6 a impotência diante do seu tratamento. Ao ser acometido pela doença renal, a única alternativa de sobrevivência no momento se apresentava com a hemodiálise, o que fez com que E1 "forçadamente" aceitasse sua realidade para melhor enfrentar a doença, como pode-se identificar na sequência discursiva acima citada. O sujeito E6 coloca que a alternativa que se encontrava para ele era a hemodiálise, demonstrando assim o sentimento de falta de autonomia diante do processo de adoecimento.

Para que as angústias e medos iniciais sejam minimizados é importante uma comunicação efetiva entre a equipe assistencial e paciente, uma vez que as reações desses são diversas e afetam significativamente no rumo da doença e tratamento. "Somente pela comunicação efetiva é que o profissional poderá ajudar o paciente a conceituar seus problemas, enfrentá-los, visualizar sua

\footnotetext{
${ }^{17}$ Com o propósito de preservar a identidade dos pacientes entrevistados, foi criado siglas para identificá-los, aonde o E equivale ao entrevistado seguido pelo ordem da entrevista, respectivamente com o sexo e idade. 
participação na experiência e alternativas de solução para os mesmos" (CAMPOS ; TURATO, 2010, p. 801).

Assim, como o tratamento, o diagnóstico é um período muito importante, é nesse período que o paciente começa um processo de reelaboração e se perceber diante da nova realidade, Campos e Turato (2010, p. 801), colocam que:

\begin{abstract}
A situação de doença funciona como uma ruptura na vida do indivíduo, ruptura nas suas relações, ruptura da sua autoimagem (...) acredito que o acolhimento inicial das angústias pessoais destes indivíduos seja de vital importância para a continuidade do tratamento, bem como da elaboração por parte da paciente de mecanismos adaptativos adequados.
\end{abstract}

Os autores supracitados falam da importância de um tempo para que o paciente consiga se reorganizar diante do diagnóstico e imperativo de tratamento dialítico, o que muitas vezes, não ocorre tendo em vista o grau avançado que a doença se encontra na maioria das vezes que são diagnosticadas.

\title{
Mudanças na Vida Advindas do Adoecimento
}

A DRC é uma enfermidade que provoca perda de autonomia do sujeito como consequência das suas diversas limitações. Há complicações desde ordens fisiológicas a psicológicas e sociais, necessitando do paciente uma nova configuração por ter que adaptar-se a essa nova condição de vida que em muito impossibilita de realizar, por vezes, atividades cotidianas. (CAMPOS; TURATO, 2010). A esse respeito é possível identificar a baixo.

\footnotetext{
Ah, mudou muita coisa. Tipo assim, que a gente não pode comer tudo, nem beber água que a água tem que ser muito pouca [...] a gente não pode mais trabalhar também (E1F48).
}

Mudou tudo [pausa], na vida da gente tudo né?, muda [pausa] mas, a gente tem que tocar [choro](E2M66).

Como se percebe nas sequências discursivas acima, uma das grandes dificuldades dos pacientes entrevistados, refere-se ao processo de adaptar às limitações impostas pela doença, seja com a alimentação, quantidade de líquidos ou por ter que deixar as atividades profissionais que antes exerciam, "Tais limitações e sintomas passam a ser sentidos por ele como uma ameaça e produzem sensações de medo e angústia" (CAMPOS; TURATO, 2010, p.800).

Para os pacientes que realizam hemodiálise e enfrentam um tratamento com complicações, os diversos sentimentos vivenciados por eles, podem se intensificar, como consequência da sua 
instabilidade do quadro de saúde. Nas sequências discursivas a seguir ao falar das mudanças provocadas pela DRC é possível identificar tal ideia.

Tudo. Não tenho mais [...] no momento até aqui eu sei que tem pessoas aqui que se dão bem no tratamento, tem outras que não dão bem, mas até o momento meu só tem dado ruim, em péssimo estado, sempre com dor, já me internei duas vezes, sangrou isso aqui, tá vendo tá horrível né? [mostra as cicatrizes das diversas fistulas mal sucedidas] (E5F45).

Muita, eu tive muitas coisas, tem muitas coisas que eu não faço, eu, inclusive, é... quando eu faço tratamento eu não chego perto da esposa, eu só chego perto dela quando [...] você entende mais ou menos, chegar perto dela e curtir mais ela, entendeu? [Relativo à atividade sexual do casal], aí as vezes não dá, não dá pra fazer muitas coisas, muitas coisas enterramos (E4M54).

A doença funciona com uma ruptura na vida do sujeito, com consequente ruptura nas relações e da autoimagem (CAMPOS; TURATO, 2010). A DRC vem com uma diversidade de agravantes que impossibilitam ou restringem o paciente de muitas atividades que antes exerciam e muitas variáveis adicionais podem influenciar negativamente como expresso na fala de E5, com complicações causadas pela fístula e um quadro de saúde instável.

Na sequência discursiva E4, pode-se identificar diante das limitações provocadas pela DRC, que no que diz respeito à atividade sexual, o paciente sente necessidade de tentar não lembrar que a doença causa indisposição e muitas vezes impotência. Ao falar desse assunto, o mesmo expressa muitas coisas enterramos, fato esse que pode se ampliar para outro aspecto de sua vida, frente à DRC quando algo não está tão satisfatório ou o paciente sente-se incapacitado; a negação torna-se presente para que a sua realidade seja menos ameaçadora ou aterrorizante.

$\mathrm{O}$ indivíduo em hemodiálise defronta-se com uma realidade intrínseca à própria convivência quase que diária com o tratamento, ao mesmo tempo, que pode aliviar a dor da doença (mesmo que momentaneamente), traz a angústia da possibilidade de finitude. A relação com máquina, passa ser dúbia, velada. [...] O paciente em hemodiálise diante da sua própria existência, enquanto ser desejante e atuante, vivência a angústia da dependência e limitações da doença e seu tratamento, e mostra a percepção desta situação em relação ao continuar a viver [...] (CAMPOS; TURATO, p. 803, p. 2010).

A identidade profissional foi uma das mais afetadas por todos os pacientes entrevistados que relataram não exercer nenhuma atividade laboral depois da DRC, assim como a impossibilidade/limitação de atividades domésticas. A alimentação e ingestão de líquido foram outros elementos identificados com muita frequência como desafiadores para adaptação dos pacientes.

De um modo geral, o que se percebe é uma perda da autonomia e de decisão frente ao adoecimento e tratamento, uma vez que o imperativo da hemodiálise torna-se indispensável para manutenção da vida. Todos esses fatores limitantes são desorganizadores e provoca nos sujeitos 
entrevistados sentimentos diversos diante da doença e das múltiplas restrições que antes não se apresentavam.

\section{O Acompanhamento Familiar}

Knobel (2008) coloca que a família funciona como um sistema que tende à homeostasia, nessa perspectiva compreende-se que quando um ente familiar encontra-se adoecido todo o grupo familiar sofre impacto. Nesse cenário a busca por estratégias e formas de enfrentamento são fundamentais para melhor lidar com o adoecimento e tratamento.

A família é um dos elementos principais, como percebido nas entrevistas, para que os pacientes consigam prosseguir no tratamento e aderir um comportamento satisfatório, verifica-se nas sequências discursivas a seguir ao falar da família no processo de cuidado.

[...] meu esposo também deu a maior força, aí conversando e explicando pra gente que não era só eu era muita gente, aí eu fui ver que aquilo ali em gente que tem problema pior do que a gente né? (E1F48).

Minha mulher ajudou muito, se não fosse ela, eu já tinha morrido [choro] e a força e coragem que Deus dá, né? Você tem que enfrentar [...] (E2M66).

Percebe-se nas sequências discursivas E1 e E2 que os parceiros foram os elementos principais para encontrarem "Forças" (palavra essa presente nas duas falas) no enfrentamento da doença. A entrevistada E1 com o apoio do seu cônjuge pode modificar sua experiência com a DRC ao perceber a partir da conversa com o marido que outras pessoas possuem um quadro de saúde mais crítico que o dela, o que a fez consolar-se por tal dado empírico.

Na sequência discursiva E2, o entrevistado encontrou "força e coragem" na esposa e em Deus, expresso na sua fala como as formas de ajudas ao descobrir a doença e procurar mecanismos para enfrentá-la, o mesmo traz na sua fala o sentimento de impotência e obrigatoriedade no que concerne ao tratamento uma vez que coloca "você tem que enfrentar" fala essa que remete a uma situação que não tem escolha, como já foi discutido anteriormente neste trabalho.

Elementos externos a família também pode ser compreendido pelo entrevistado como uma fonte de apoio para enfrentamento da doença, como se percebe na sequência discursiva a seguir.

Rapaz, o governo me ajudou, pode ser ajuda que eles me deram o beneficio, me deram parece que oito meses de beneficio, ai eu não consegui ficar bom, ai eles me deram mais oito meses, daí foi eles me seguraram até agora (E4M54).

Considerando que doença traz diversas limitações e afastamentos das atividades laborais do paciente, o mesmo se ver imerso em diversas dificuldades de ordem, fisiológicas, psicológicas, sociais 
e econômicas. Nesse sentido E4, paciente do sexo masculino de cinqüienta e quatro anos, traz em sua fala a maior preocupação que refere a questões financeiras, como prover o lar.

Inquietação essa que pode ser comum uma vez que sua imagem como homem ativo no lar, encontra-se comprometida com a doença, e o mesmo, pode sentir-se com a imagem ameaçada, e a necessidade de preocupar-se com dinheiro ou benefício, pode ser reflexo de sua condição para manter sua posição de sujeito atuante e provedor da casa, como expresso em sua entrevista, onde frequentemente o medo de não conseguir dá o básico para sua esposa o amedronta.

\section{Adoecimento e Espiritualidade}

Frankl (1992) fala de um "inconsciente transcendente" onde sempre houve nos indivíduos uma tendência inconsciente em direção de Deus, uma ligação intencional, embora inconsciente com Deus, que em muitas vezes essa relação pode ser inconsciente ou reprimida para o próprio sujeito. Nesse sentido, pode-se inferir que o sofrimento proporciona esse contato com o deus que em muitos indivíduos não estava tão presente de forma consciente.

Estudos de Coelho (2011, apud SAPORETTI, 2009, p.271) ao falar da espiritualidade, mostram que:

A dimensão espiritual relaciona o existencial com o transcendente, seja ele Deus, a natureza, o sobrenatural ou sagrado. O sofrimento humano pode nascer em qualquer dessas dimensões e é integrado pelo significado e sentido associado a ele.

$\mathrm{O}$ adoecimento por provocar sofrimento e muitas vezes colocar o sujeito frente às suas fragilidades e medos, requer que o mesmo encontre estratégias para enfrentá-lo, dando sentidos as suas experiências de perdas. Nessa perspectiva, pode-se identificar nas sequências discursivas a seguir que "Deus", apresenta-se como palavra marcante e fundamental no que diz respeito à fonte de forças e ajudas encontradas pelos entrevistados.

Deus. Só deus, por que [...] é triste, vamos levar até ele querer [choro] (E2M66).

O que deu forças pra eu enfrentar a doença dos rins?![...] rapaz eu sei lá, [sorrir] [pausa] Deus me deu muita coragem pra mim enfrentar essa doença, eu digo na... e pedi muita fortuna a Deus pra ele me dá força e coragem até resistir (E3F41).

A fé em Deus, porque o que eu tinha de mais precioso pra mim, ele já levou que foi minha mãe né? [choro]. A fé nele, um dia de alguma forma vai ser solucionado o problema, da forma que ele achar melhor (E5F45).

A liberdade interior é de uso exclusivo do sujeito, para isso o mesmo pode modificar a forma de enxergar a sua realidade, na tentativa de ampliar seu horizonte de possibilidades, sendo capaz de 
transcender e viver melhor transformando seu sofrimento em triunfo pessoal (FRANKL, 2008).

Pode-se compreender melhor o que o autor trouxe anteriormente na fala de E5, ao expor de forma clara a possibilidade de cura pela sua fé em Deus, esse que pode solucionar o problema, da forma que achar melhor como expresso pela entrevistada. Essa possibilidade de cura de certo modo proporciona o bem-estar da paciente, uma vez que sua esperança, em certa medida, encontra-se respaldada em uma possível melhora, possibilitando que a mesma encontre um sentido na sua dor, com um possível distanciamento, das máquinas de hemodiálise ou da própria DRC.

Gomes (1992) aborda que a Logoterapia, corrente psicológica criada por V. E. Frankl é muito útil ao atendimento de pacientes que se encontram com falta de sentidos, no entanto ela "não é uma solução única [...] mas uma tentativa de ajudar a encontrar um sentido para a vida de cada pessoa, na sua realidade, em seu sofrimento, em sua existência, muitas vezes desprovida de propósitos" (GOMES, 1992, p. 27).

Quando o autor fala da busca do sentido para a vida, o mesmo se atenta para o entendimento que não se trata de um sentido especifico, mas sim "do" sentido, que já é existente, basta resgatá-lo. Sentido esse que é individual e singular a cada sujeito que possui uma missão na vida, o seu "para que" viver (FRANKL, 2008).

De acordo com o supracitado, torna-se muito importante que os sujeitos encontrem sentido diante de suas vivências e sofrimentos. Percebe-se que a espiritualidade e a fé em Deus proporcionam uma força para que os mesmos consigam prosseguir no tratamento. Sendo assim, as escolhas em continuar vivendo, recebe influências que, primeiramente vem com Deus, depois a família e/ou cônjuge e amigos, que em muito contribuem para o bem-estar do paciente.

Campos e Turato (2010) colocam que diante da doença renal crônica, o individuo se ver frente a uma escolha para continuar a existir, escolha essa que em muito simboliza como uma salvação. Diante dessa escolha que é "impessoal" como abordado pelo autor, foi verificado pelas entrevistas que elementos como "Deus", "Cônjuge e/ou família" e "Amigos" influencia em certa medida para que a escolha de continuar ou não o tratamento seja efetivada.

\section{Considerações Finais}

Trabalhar as imagens acerca da doença renal elaborada pelos próprios pacientes é de fundamental importância para que se consiga acessar o seu imaginário, percepções e as formas que lidam com a doença, para que as terapêuticas se tornem uma intervenção eficaz.

A doença renal crônica provoca no indivíduo uma série de mudanças nas diversas áreas da sua vida que requer uma adaptação "forçada", uma vez que o imperativo da hemodiálise se apresenta como uma forma de salvação ou manutenção da vida. 
Pode-se compreender de que forma o paciente renal crônico lida com o seu processo de adoecimento, na medida em que se identificou o impacto do diagnóstico e das mudanças na vida dos mesmos, e os mecanismos para enfrentamento. O desconhecimento do tratamento hemodialítico, a ruptura do estilo de vida, a necessidade de uma adaptação e uma série de restrições são os elementos que mais contribuíram na forma que o sujeito lida com sua doença.

A família de um modo geral, incluindo cônjuge, filhos e parentes, contribuem em muito para um suporte, seja na descoberta da doença, durante o tratamento ou na busca de estratégias para enfrentar a cronicidade da mesma. A espiritualidade, mas especificamente a figura de "Deus" veio muito presente como uma "força" que contribui para a busca de sentidos e ressignificar o sofrimento.

Uma terapêutica que vise um resgate de sentidos para o sofrimento do indivíduo, assim como uma boa relação da equipe assistencial para com o paciente, apresentou-se como importante também neste cenário de cuidado.

A doença renal crônica vem como um evento que é visto pelos entrevistados como "divisor de águas", uma vez que quando é detectada a perda da função renal, muitas outras perdas vêm juntas ao diagnostico da doença, perdas simbólicas e reais, da função social, do papel que ocupa, seja na família, no trabalho ou na sociedade, assim como perda da própria autoimagem.

A tentativa de compreender o "mundo" dos pacientes renais crônicos torna-se importante para que a partir de suas percepções e necessidades acerca da DRC consiga-se realizar terapêuticas que proporcionem uma melhor qualidade de vida para esses indivíduos.

Não se pretendeu com esse estudo esgotar as discussões sobre esse tema. O pesquisador pretende ampliar o estudo futuramente, assim como torna-se interessante que outros pesquisadores continuem a estudarem sobre o tema para que novas propostas de intervenções sejam voltadas para a real necessidade dos pacientes.

\section{Referências}

BASTOS, M. G.; BREGMAN, R.; KIRSZTAJN. G. M. Doença renal crônica: frequente e grave, mas também prevenível e tratável. Rev. Assoc. Med.Bras. 56.2 São Paulo, 2010: 248-53

CAMPOS, C. J. G.; TURATO, E. R. Tratamento hemodialítico sob a ótica do doente renal: estudo clínico qualitativo. Revista Brasileira de Enfermagem 63.5 (2010): 799-805.

COELHO, M. E. de M., Espiritualidade no processo de adoecimento e terminalidade. 2011. $210 \mathrm{f}$. Dissertação (Mestrado) - Programa de Pós-Graduação em Ciências da Religião, Pontifícia Universidade Católica de Minas Gerais. Belo Horizonte. 2011.

DEMARTINI, Z. Histórias de vida na abordagem de problemas educacionais. In.: SIMSON, O. R. (org.). Experimentos em histórias de vida. São Paulo: Revista dos Tribunais, 1988. 
FERREIRA, H. P. et al. O impacto da doença crônica no cuidador. Revista da Sociedade Brasileira de Clínica Médica. 10.4. Jul.-Ago. 2012: 278-84.

FRANKL, V. E. A presença Ignorada de Deus. Trad. de Walter O. Schlupp e Helga H. Reinhold. São Leopoldo, Editora Sinodal; Petrópolis, Editora Vozes, 1992.

FRANKL, V. E. Em busca de sentido: um psicólogo no campo de concentração / Viktor E. Frankl. Traduzido por Walter O. Schlupp e Carlos C. Aveline. 25. Ed. - São Leopoldo: Sinodal; Petrópolis: Vozes, 2008

FREITAS, P. P. W; COSMO, M. Atuação do Psicólogo em Hemodiálise. Rev. SBPH v.13 n.1, Rio de Janeiro, Jun. 2010.

GIL, A. C. Como Elaborar Projetos de Pesquisa. 5 Edição, ATLAS, São Paulo, 2010

GOMES, J. C. V. Logoterapia: A Psicoterapia Existencial Humanista de Viktor Emil Frankl. São Paulo: Edições Loyola, 1992.

HIGA, K. et al. Qualidade de Vida de Pacientes Portadores de Insuficiência Renal Crônica em Tratamento de Hemodiálise. Acta Paul Enferm (online) 2008; 21(Número Especial): p. 203-206

KNOBEL, E. Psicologia e Humanização: assistência a pacientes graves / Elias Knobel, Paola B. de Araujo Andreoli, Manes R. Erlichman. - São Paulo, Atheneu, 2008.

KUBLER-ROSS, E. Sobre a morte e o morrer: o que os doentes terminais têm para ensinar a médicos, enfermeiros, religiosos e aos seus próprios parentes / Elisabeth Kubler-Ross; [tradução Paulo Menezes]. - 9a. Ed. - São Paulo: Editora WMF Martins Fontes, 2008.

MARCONI, M. de A; LAKATOS, E. M. Fundamentos de Metodologia Científica. $7^{a}$ Edição, ATLAS, São Paulo, 2010.

MARCONI, M. de A; LAKATOS, E. M. Metodologia Científica. $6^{a}$ Edição, ATLAS, São Paulo, 2011.

MASCARENHAS, C. H. M. et al. Insuficiência renal crônica: caracterização sociodemográfica e de saúde de pacientes em tratamento hemodialítico no município de Jequié/BA. Espaço para a Saúde 12.1. 2011: 30-37.

MELO FILHO, J. de. Psicossomática Hoje / Júlio de Melo Filho [et al]. 2. Ed. - Porto Alegre : Artmed, 2010.

RESENDE, M. C. et al. Atendimento Psicológico a Pacientes com insuficiência Renal Crônica: Em Busca de Ajustamento Psicológico. Psic. Clin. Rio de Janeiro, Vol.19, N.2, P.87 - 99, 2007.

ROMÃO JUNIOR, J. E. Doença Renal Crônica: Definição, Epidemiologia e Classificação. J. Bras. Nefrol. 2004; 26 (3Suppl 1): 1-3. Disponível em: <http://www.jbn.org.br/ detalhe_artigo.asp?id=1183> Acesso em: 07 de Agosto de 2014.

TAKEMOTO, A. Y. et al. Avaliação da qualidade de vida em idosos submetidos ao tratamento hemodialítico. Rev Gaúcha Enferm (online) 32.2 vol.32 no.2 Porto Alegre Junho 2011. 
ID on line REVISTA DE PSICOLOGIA

http://idonline.emnuvens.com.br/id

ISSN on-line: $1981-1179$

isen line

\section{Como citar este artigo (Formato ABNT):}

LIMA, S.E.S.; LIMA JÚNIOR, J. o Imaginário dos Pacientes acerca da Doença Renal Crônica. Id on Line Revista de Psicologia, Julho de 2015, vol.9, n.27. p. 82-97. ISSN 1981-1189.

Recebido: $15 / 05 / 2015$

Aceito:19/05/2015 